\title{
Response of Helicobacter Pylori Eradication Treatment in Patients With Normal and Below- Normal Serum Vitamin D Levels
}

Irshad Magsi ${ }^{1}$, Shakir Hussain keerio ${ }^{2}$, Chandar Kumar ${ }^{3}$, Abdul Subhan Talpur ${ }^{3}$, Fnu Shahzeen ${ }^{4}$, Zohra Mushtaq Abbasi ${ }^{5}$, Munisha Lohano ${ }^{6}$, Vijay Kumar ${ }^{2}$, Amber Rizwan ${ }^{7}$

1. Internal Medicine, Baqai Medical University, Karachi, PAK 2. Internal Medicine, Liaquat University of Medical and Health Sciences, Jamshoro, PAK 3. Medicine, Liaquat University of Medical and Health Sciences, Jamshoro, PAK 4. Internal Medicine, Jinnah Sindh Medical University, Karachi, PAK 5. Research and Statistics, Shaheed Zulfikar Ali Bhutto Institute of Science and Technology, Karachi, PAK 6. Interventional Cardiology, Liaquat University of Medical \& Health Sciences, Jamshoro, PAK 7. Family Medicine, Jinnah Post Graduate Medical Center, Karachi, PAK

Corresponding author: Chandar Kumar, chandarkumarr@yahoo.com

\section{Abstract}

\section{Introduction}

The infection of Helicobacter pylori (H. pylori) is affected by the host immune system and the genetic makeup. It is postulated that deficiency of vitamin D may interfere in normal immunological response to infectious agents, including $H$. pylori, and increase the risk of infection. This study aims to find the relationship between vitamin D status in the body and patient's response to $H$. pylori eradication treatment.

\section{Methods}

One hundred and fifty patients $(\mathrm{n}=150)$ between the ages of 18 and 60 years of either gender, diagnosed with $H$. pylori, were included in the study. After enrollment, patients were started on first-line eradication therapy, which included omeprazole, amoxicillin, and clarithromycin for 14 days. Patient's vitamin D levels were tested via laboratory. After 14 days, patients' stools were tested for presence of $H$. pylori antigen.

\section{Results}

A total of 128 participants completed the study, out of which 92 (71.8\%) participants showed no H. pylori antigen in stool after 14 days and 36 (28.1\%) participants still showed H. pylori in their stool. The mean serum vitamin D level was significantly higher in participants who had successful treatment compared to those who had unsuccessful treatment $(31.01 \pm 7.8 \mathrm{ng} / \mathrm{mL}$ vs. $18.9 \pm 5.6 \mathrm{ng} / \mathrm{mL}$; p-value $<0.0001)$.

\section{Conclusion}

Vitamin D levels may affect the response of H. pylori eradication therapy. Further large-scale studies are

Review began 04/26/2021 Review ended 04/27/2021 Published 04/30/2021

\section{() Copyright 2021}

Magsi et al. This is an open access article distributed under the terms of the Creative Commons Attribution License CC-BY 4.0., which permits unrestricted use, distribution, and reproduction in any medium, provided the original author and source are credited. needed in which vitamin $\mathrm{D}$ is given as an intervention to further study the association between vitamin $\mathrm{D}$ levels and $H$. pylori treatment response.

Categories: Internal Medicine, Gastroenterology

Keywords: vitamin d, treatment response, association, pakistan, helicobacter pylori

\section{Introduction}

Helicobacter pylori (H. pylori) is a spiral-shaped gram-negative microaerophilic bacterium first described in 1983 [1]. Today it affects almost 50\% of the world's population by colonizing the human gastric mucosa. It has been established as a major culprit of chronic gastritis and has also been identified to play an essential role in the pathogenesis of several other gastric conditions like peptic ulcer disease, gastric adenocarcinoma, and mucosa-associated lymphoid lymphoma [2,3]. Almost $90 \%$ of duodenal ulcers and over three-fourths of gastric carcinomas are associated with $H$. pylori infections [4]. In patients with a positive family history of gastric cancers, the cancer incidence is seen to decline with the eradication of the infection $[2,3]$.

Although $H$. pylori infection has a high global prevalence, it is inversely associated with socioeconomic development, more commonly affecting the developing world [5]. Like most other infectious diseases of the gastrointestinal tract, it also has an oral-fecal route of transmission [6]. The infection warrants timely treatment to hamper the recurrence and avoid the accompanying complications [7]. The preferred treatment, called triple therapy, includes one proton-pump inhibitor (PPI) with a combination of antibiotics like clarithromycin and amoxicillin (or metronidazole) [8]. The cure rate with triple therapy ranges from $75 \%$ to $85 \%$; however, in recent times, this has fallen to a lower percent, attributed to the development of new antibiotic-resistant strains $[9,10]$. 


\section{Cureus}

The infection of $H$. pylori is also affected by the host immune system and the genetic makeup [11]. Vitamin $\mathrm{D}$, a widely recognized mediator of bone metabolism in the human body, also plays an important role in immunoregulation and inflammation. Studies have shown that vitamin D plays a vital part in the expression of genes coding for antimicrobial proteins (AMPs), which then modulate immune responses to various infections $[12,13]$. Therefore, the deficiency of vitamin D may be implicated to hamper the normal immunological response to infectious agents, including H. pylori, and increase the risk of infection $[11,13]$. As limited literature exists on the impact of vitamin D deficiency in $H$. pylori infections, this study aims to find the relationship between the vitamin D status in the body and patient's response to $H$. pylori eradication treatment.

\section{Materials And Methods}

This study was conducted in the gastroenterology ward of a tertiary care hospital in Pakistan from March 2019 to January 2020. One hundred and fifty patients $(n=150)$ between the ages of 18 and 60 years of either gender diagnosed with $\mathrm{H}$. pylori were included in the study. Helicobacter pylori was diagnosed with giemsastained gastric biopsy specimens. Patients already on antibiotics, PPI, or vitamin D supplements were not included in the study. Patients were enrolled via consecutive convenient non-probability sampling. After enrollment, patients were started on first-line eradication therapy, which included omeprazole, amoxicillin, and clarithromycin for 14 days. Patient's blood was drawn via phlebotomy and was sent to the laboratory for vitamin D levels. Vitamin D levels of less than $30 \mathrm{ng} / \mathrm{mL}$ were classified as hypovitaminosis [14]. Patients were followed up after 14 days and their stool was assessed for $H$. pylori antigen, using rapid test, to confirm eradication. If the antigen test was negative, treatment was labelled as successful. Compliance to medication was checked and confirmed with patients that if they have completed their treatment regime and no dose was missed. A total of 22 participants were lost to follow-up and only participants who completed the study were included in the final analysis.

Statistical analysis was done using Statistical Package for the Social Sciences (SPSS) v. 22.0 (IBM Corporation, Armonk, NY, United States). Continuous variables were tabulated as mean and standard deviation. Categorical variables were presented as percentages and frequencies. Independent $t$-test or chi square was applied as deemed appropriate. A p-value of less than 0.05 represented a difference between the two groups and the null hypothesis was void.

\section{Results}

One hundred and twenty-eight $(\mathrm{n}=128)$ participants completed the study. Ninety-two $(71.8 \%)$ participants showed no $H$. pylori antigen in stool after 14 days, whereas 36 (28.1\%) participants still showed H. pylori in their stool. Their demographics were comparable (Table 1).

\begin{tabular}{|c|c|c|c|}
\hline Demographics & Successful Treatment $(n=88)$ & Unsuccessful Treatment $(n=36)$ & p-Value \\
\hline \multicolumn{4}{|l|}{ Gender } \\
\hline Male & 42 (47.7\%) & $18(50.0 \%)$ & \multirow{3}{*}{0.05} \\
\hline Female & 46 (52.3\%) & $18(50.0 \%)$ & \\
\hline \multicolumn{3}{|c|}{ Age group (in years) } & \\
\hline $18-30$ & $21(23.9 \%)$ & $8(22.2 \%)$ & \multirow{4}{*}{0.94} \\
\hline $31-40$ & 32 (36.4\%) & $15(41.6 \%)$ & \\
\hline 41-50 & $20(22.7 \%)$ & $8(22.2 \%)$ & \\
\hline $51-60$ & $15(17.0 \%)$ & $5(13.8 \%)$ & \\
\hline
\end{tabular}

TABLE 1: Comparison of demographics of participants who underwent treatment

The mean serum vitamin D level was significantly higher in participants who had successful treatment compared to those who had unsuccessful treatment $(31.01 \pm 7.8 \mathrm{ng} / \mathrm{mL}$ vs. $18.9 \pm 5.6 \mathrm{ng} / \mathrm{mL}$; p-value < 0.0001). Number of participants with hypovitaminosis D were significantly more in the group with unsuccessful treatment (72.2\% vs. $44.3 \%$; p-value: 0.004 ) (Table 2). 


\section{Cureus}

\begin{tabular}{|c|c|c|c|}
\hline Vitamin D Status & Successful Treatment $(n=88)$ & Unsuccessful Treatment $(n=36)$ & p-Value \\
\hline Mean vitamin D level (ng/mL) & $31.01 \pm 7.8$ & $18.9 \pm 5.6$ & $<0.0001$ \\
\hline No of participants with hypovitaminosis D & $39(44.3 \%)$ & $26(72.2 \%)$ & 0.004 \\
\hline ng, nanogram; mL, milliliter. & & & \\
\hline
\end{tabular}

\section{Discussion}

In our study, patients were treated to eradicate $H$. pylori. Women had a higher successful treatment rate $(52.3 \%)$ as compared to men (47.7\%). People belonging to the age group 31-40 were more likely to respond positively to the eradication therapy (36.4\%), followed by the age group 18-30 (23.9\%). Our study also demonstrated that successful treatment had a positive correlation with elevated vitamin D levels in the serum.

A number of studies provide evidence that vitamin D plays a major role in eradicating H. pylori. A study showed that vitamin D3 decomposition product (VDP1) selectively affects H. pylori, but did not affect the survival of Enterobacteriaceae bacteria, Pseudomonas aeruginosa, or Staphylococcus aureus in any way [15]. Several studies are of the idea that dimyristoyl phosphatidylethanolamine (DMPE), a common glycerophospholipid, is a major component of the cell membrane of $H$. pylori [16], and VDP1 results in dissolving bacteria by coming in contact with DMPE of $H$. pylori membrane. Another study proved that one of the products of vitamin D decomposition, alkyl of indene, interconnects with the di-14:0 DMPE of $H$. pylori. This leads to the breakdown, and the absence of alkyl proved the eradication of the germicidal effect on $H$. pylori [17]. Several studies suggested that serum vitamin D levels could potentially affect $H$. pylori eradication $[18,19]$. These studies provided evidence that decreased level of vitamin $\mathrm{D}$ is strongly associated with failure of $H$. pylori eradication.

The possible explanation of pathogenesis is that the close link between vitamin $\mathrm{D}$ level and eradication is that the disablement of vitamin D signals the immune system, causing insufficient immune response [8]. Apart from its effect on bones, vitamin D is known to decrease inflammatory markers like C-reactive protein, tumor necrosis factor- $\alpha$, interleukin 6 , and interleukin 18 , and the level of anti-inflammatory cytokine interleukin 10 may increase [20]. It is also known to monitor the expression of AMPs cathelicidin and $\beta$ defensin, which are known to cause bacterial death. Therefore, it is said that low levels of vitamin D could result in failure of $H$. pylori due to reduced immune response, which make the conditions favorable for the bacteria.

The study has its limitations as well. First, since it was a single center the sample was less diverse. Secondly, the impact of vitamin D supplement was not studied on eradication of $H$. pylori. Keeping in mind the aforementioned facts, further large-scale studies are required to explore vitamin D levels and its effect on $H$. pylori eradication. In cases of infection, vitamin D levels should be checked at regular intervals. In cases of its deficiency, it is advised to introduce vitamin D supplements to eliminate the chances of its deficiency worsening the cases.

\section{Conclusions}

Our study demonstrated that vitamin D levels in $H$. pylori-negative patients were higher than the $H$. pylori-positive patients. Furthermore, a positive correlation was found between successful eradication therapy and elevated vitamin D levels in the serum. Hence, we conclude that vitamin D levels may affect the response of $H$. pylori eradication therapy. Further large-scale studies are needed in which vitamin D is given as an intervention to further study the association between vitamin D levels and $H$. pylori treatment response, and to associate low vitamin D levels as a risk factor of treatment failure of $H$. pylori.

\section{Additional Information \\ Disclosures}

Human subjects: Consent was obtained or waived by all participants in this study. Liaquat University of Medical and Health Sciences issued approval LUMHS/IM/19-17. Animal subjects: All authors have confirmed that this study did not involve animal subjects or tissue. Conflicts of interest: In compliance with the ICMJE uniform disclosure form, all authors declare the following: Payment/services info: All authors have declared that no financial support was received from any organization for the submitted work. Financial relationships: All authors have declared that they have no financial relationships at present or within the previous three years with any organizations that might have an interest in the submitted work. 
Other relationships: All authors have declared that there are no other relationships or activities that could appear to have influenced the submitted work.

\section{References}

1. Marshall BJ, Warren JR: Unidentified curved bacilli in the stomach of patients with gastritis and peptic ulceration. Lancet. 1984, 1:1311-5. 10.1016/s0140-6736(84)91816-6

2. Go MF: Review article: natural history and epidemiology of Helicobacter pylori infection . Aliment Pharmacol Ther. 2002, 16:3-15. 10.1046/j.1365-2036.2002.0160s1003.x

3. Malfertheiner P, Link A, Selgrad M: Helicobacter pylori: perspectives and time trends. Nat Rev Gastroenterol Hepatol. 2014, 11:628-38. 10.1038/nrgastro.2014.99

4. Rana R, Wang SL, Li J, Wang YX, Rao QW, Yang CQ: Helicobacter pylori infection: A recent approach to diagnosis and management. J Biomed. 2017, 2:45-56. 10.7150/jbm.17612

5. Bener A, Uduman SA, Ameen A, et al.: Prevalence of Helicobacter pylori infection among low socioeconomic workers. J Commun Dis. 2002, 34:179-84

6. Brown LM: Helicobacter pylori: epidemiology and routes of transmission. Epidemiol Rev. 2000, 22:283-97. 10.1093/oxfordjournals.epirev.a018040

7. NIH Consensus Conference. Helicobacter pylori in peptic ulcer disease. NIH Consensus Development Panel on Helicobacter pylori in Peptic Ulcer Disease. JAMA. 1994, 272:65-9.

8. Chey WD, Wong BC; Practice Parameters Committee of the American College of Gastroenterology: American College of Gastroenterology guideline on the management of Helicobacter pylori infection . Am J Gastroenterol. 2007, 102:1808-25. 10.1111/j.1572-0241.2007.01393.x

9. Feng L, Wen MY, Zhu YJ, Men RT, Yang L: Sequential therapy or standard triple therapy for Helicobacter pylori infection: an updated systematic review. Am J Ther. 2016, 23:e880-93. 10.1097/MJT.0000000000000191

10. Gatta L, Vakil N, Vaira D, Scarpignato C: Global eradication rates for Helicobacter pylori infection: systematic review and meta-analysis of sequential therapy. BMJ. 2013, 347:f4587. 10.1136/bmj.f4587

11. Ishizaki T, Horai Y: Review article: cytochrome P450 and the metabolism of proton pump inhibitors-emphasis on rabeprazole. Aliment Pharmacol Ther. 1999, 13:27-36. 10.1046/j.1365-2036.1999.00022.x

12. Kitson MT, Roberts SK: D-livering the message: the importance of vitamin D status in chronic liver disease . J Hepatol. 2012, 57:897-909. 10.1016/j.jhep.2012.04.033

13. Liu PT, Stenger S, Li H, et al.: Toll-like receptor triggering of a vitamin D-mediated human antimicrobial response. Science. 2006, 311:1770-3. 10.1126/science.1123933

14. Mansoor F, Kumar V, Kumar S, et al.: Association between serum vitamin D levels and frequency of relapses in patients with multiple sclerosis. Cureus. 2021, 13:e14383. 10.7759/cureus.14383

15. Hosoda K, Shimomura $\mathrm{H}$, Wanibuchi $\mathrm{K}$, et al.: Identification and characterization of a vitamin $\mathrm{D}_{3}$ decomposition product bactericidal against Helicobacter pylori. Sci Rep. 2015, 5:8860. 10.1038/srep08860

16. Malfertheiner P, Mégraud F, O'Morain C, et al.: Current concepts in the management of Helicobacter pylori infection--the Maastricht 2-2000 Consensus Report. Aliment Pharmacol Ther. 2002, 16:167-80. 10.1046/j.1365-2036.2002.01169.x

17. Wanibuchi $\mathrm{K}$, Hosoda $\mathrm{K}$, Ihara $\mathrm{M}$, et al.: Indene compounds synthetically derived from vitamin $\mathrm{D}$ have selective antibacterial action on Helicobacter pylori. Lipids. 2018, 53:393-401. 10.1002/lipd.12043

18. Yildirim O, Yildirim T, Seckin Y, Osanmaz P, Bilgic Y, Mete R: The influence of vitamin D deficiency on eradication rates of Helicobacter pylori. Adv Clin Exp Med. 2017, 26:1377-81. 10.17219/acem/65430

19. El Shahawy MS, Hemida MH, El Metwaly I, Shady ZM: The effect of vitamin D deficiency on eradication rates of Helicobacter pylori infection. JGH Open. 2018, 2:270-5. 10.1002/igh3.12081

20. Yagi K, Nakamura A, Sekine A: Comparison between magnifying endoscopy and histological, culture and urease test findings from the gastric mucosa of the corpus. Endoscopy. 2002, 34:376-81. 10.1055/s-200225281 